\title{
ANÁLISE DAS DEMONSTRAÇÕES CONTÁBEIS: UMA ESTRUTURA DE AVALIAÇÃO DE DESEMPENHO DAS COMPANHIAS BRASILEIRAS PELOS PRIVATE EQUITY A PARTIR DAS INFORMAÇÕES DIVULGADAS
}

\section{ANALYSY OF THE FINANCIAL STATEMENTS: A PERFORMANCE VALUATION OF THE BRAZILIAN COMPANIES BY THE PRIVATE EQUITY BASED ON THE INFORMATION DISCLOSURED}

\author{
Recebimento: 02/07/2017- Aceite: 04/11/2017- Publicação: 23/12/2017 \\ Processo de Avaliação: Double Blind Review
}

Adriana Caetano ${ }^{1}$

Mestre em Ciências Contábeis pela Fundação Escola de Comércio Álvares Penteado (FECAP)

adriana.caetano@hotmail.com

Anísio Candido Pereira

Vice Coordenador e Professor Doutor do Programa de Mestrado em Ciências Contábeis da Fundação Escola de Comércio Álvares Penteado (FECAP)

profanisio@fecap.br

Marcos Reinaldo Severino Peters

Doutor em Controladoria e Contabilidade pela Universidade de São Paulo.

marcospeters@marpet.com.br

Fernando de Almeida Santos

Professor do Mestrado em Ciências Contábeis e Atuariais da Pontifícia Universidade Católica (PUC-SP)

Pesquisador do NUPE-Centro Universitário ENIAC

almeidasantos@pucsp.br

\section{RESUMO}

Os private equity analisam as demonstrações financeiras de maneira objetiva, prática, focando as informações quantitativas e, com certa frequência, têm sido surpreendidos por situações que não estavam registradas nas demonstrações contábeis, mas somente divulgadas e que afetam a rentabilidade de seus investimentos. Diante do exposto, o objetivo deste estudo foi desenvolver uma estrutura de avaliação de desempenho de companhias brasileiras, corroborada com as informações divulgadas em suas demonstrações financeiras, a fim de auxiliar os investidores de private equity em estimar o valor de uma entidade. Para construção da pesquisa foi realizada pesquisa bibliográfica, com a finalidade de identificar os elementos relevantes na avaliação das empresas e foi desenvolvida a referida estrutura. Efetuou-se, ainda, uma triangulação entre os itens mencionados na estrutura de avaliação de desempenho e as informações apresentadas nas demonstrações financeiras das quatro empresas registradas no Bovespa Mais, dos segmentos de Energia Renovável e Tecnologia da Informação. Obteve-se como amostra as demonstrações

\footnotetext{
${ }^{I}$ Autor para correspondência: Fundação Álvares Penteado - FECAP, Largo São Francisco, 19 - Sé, São Paulo SP, Brasil- 01003-000
}

Revista ENIAC Pesquisa, Guarulhos (SP), V.6, n.2, jun.- dez. 2017 
financeiras com exercício em 31.12.2014 das empresas listadas no Bovespa Mais, que atuam nos segmentos de energia e energias renováveis, agronegócio e tecnologia da informação, sendo essas: a) Energia Renovável: Cia Águas do Brasil - CAB Ambiental e Desenvix Energias Renováveis S. A.; b) Tecnologia da Informação: Quality Software S.A. e Senior Solution S.A. Observou-se que há um o alto índice da presença dos itens da estrutura desenvolvida nas demonstrações financeiras das empresas analisadas, o que corrobora a possibilidade de utilização de tal estrutura no processo de estimação do valor de uma empresa.

PALAVRAS-CHAVES: Valuation; Avaliação de desempenho; Informações divulgadas; Private equity.

\section{ABSTRACT}

Private equity analyze the financial statements in an objective and practical way, focusing on the quantitative information and, frequently, are surprised by non-recorded situations, but only disclosed ones that affect the profitability of its investments. Therefore, the objective of this study was to develop a performance analysis structure of the Brazilian companies, based on the literature, corroborated by the information disclosed in their financial statements in order to supporting the private equity investors to estimate the value of an entity. It was made a bibliographic research, aiming to identify the relevant elements to valuate a company, what resulted in the developed referred structure. It was performed a cross check between the terms presented in the performance analysis structure and the content presented in the financial statement of the four companies registered in the Bovespa Mais, part of the Clean Energy and Information Technology segments. Observed a high level index of presence of the items part of the developed structure in the financial statements of the analyzed companies, which corroborate the possibility of using such structure in the process of estimating the value of a company.

KEY-WORDS: Valuation; Performance analysis; Disclosure; Private equity.

\section{INTRODUÇÃO}

Atualmente, as demonstrações financeiras apresentam um grande volume de informações, algumas vezes repetitivas, dispersas, o que pode dificultar a identificação da informação relevante para a análise de desempenho de uma empresa. Por causa disso, pode-se inferir que, em alguns casos, as demonstrações financeiras têm de ser decodificadas, transformando-se em signos identificáveis e inteligíveis.

Os private equity são Fundos de Investimento em Participações (FIP) com recursos destinados à aquisição de ações, debêntures, bônus de subscrição, ou outros títulos e valores mobiliários conversíveis ou permutáveis em ações de emissão de companhias, que participam no processo decisório dessas, com efetiva influência na administração.

Ao considerar que o objetivo dessas entidades é investir em empresas para obter retornos acima da média do mercado, o processo de escolha da empresa investida é uma etapa 
fundamental, sendo uma das partes mais importantes deste processo, o valuation, isto é, a estimação de seu valor.

Para isso, os private equity analisam as demonstrações financeiras das empresas de modo objetivo, prático, dando muito mais atenção aos quadros e principalmente às informações quantitativas, o que, algumas vezes, os surpreendem, já que situações derivadas de assuntos mais sensíveis e específicos, muitas vezes, não estão registradas, são somente, divulgadas.

Este estudo, então, desenvolve uma estrutura de avaliação de desempenho de companhias brasileiras a partir da bibliografia, corroborada com as informações divulgadas em suas demonstrações financeiras, a fim de auxiliar os investidores de private equity a estimar o valor de uma entidade, isto é, valuation.

Assim, este artigo é divido em cinco partes. Após esta introdução, que demonstra a contextualização do tema e o objetivo, apresenta: o referencial teórico na parte 2 , que aborda a indústria de private equity, os modelos de avaliação de empresas pelo fluxo de caixa descontado e as questões relevantes na avaliação de empresas relacionadas às informações divulgadas nas demonstrações contábeis; a metodologia da pesquisa na parte 3; as análises e os resultados encontrados na parte 4; e, por fim, as considerações finais e sugestões para novas pesquisas a partir deste estudo.

\section{REFERENCIAL TEÓRICO}

\subsection{A INSDÚSTRIA DE PRIVATE EQUITY}

No Brasil, os private equity são fundos de investimento em participações (FIP), condomínios fechados administrados por gestores independentes, regulados e supervisionados pela CVM; constituídos na forma de comunhão de ativos pertencentes aos cotistas do fundo, que não têm a propriedade direta sobre esses ativos, somente têm direito a carteira de investimento, proporcionalmente ao número de cotas que detêm. (CVM, 2003)

Este deve manter, no mínimo, 90\% de seu patrimônio investido em ações, debêntures, bônus de subscrição, ou outros títulos e valores mobiliários conversíveis ou permutáveis em ações de emissão de companhias, abertas ou fechadas. Logo, não pode desviar de seu foco, ou seja, o investimento em empresas.

Nota-se que é marcante a evolução da indústria de private equity neste país. De 2011 para 2013, o capital investido pelos private equity em empresas aumentou 31\%. (KPMG, 2014). De acordo com a ABVCAP (2015), houve um crescimento de 35,4\% do capital disponível nos fundos para investimento em 2014, se comparado a 2013, chegando a $\mathrm{R} \$ 36,8$ bilhões.

Smolarski, Wilner e Yang (2011) afirmam que os administradores e gestores dos fundos efetuam uma avaliação da empresa, contemplando: (a) a análise do negócio e do mercado; (b) a análise do perfil dos gestores e da equipe; (c) a avaliação financeira; (d) uma diligência - due diligence e (f) o valuation: estimação de valor da empresa e retorno a ser obtido.

Os private equity investem o dinheiro de terceiros em ações, debêntures, bônus de subscrição e outros títulos e valores mobiliários conversíveis em ações, emitidos por companhias que demonstram grande potencial de crescimento, recebendo ações/quotas que lhes proporcionam influência significativa e, assim, atuar na administração e na gestão da entidade 
a fim de alavancar o negócio e maximizar os retornos para seus investidores. Logo, o processo de escolha da empresa investida e a estimação de seu valor são fundamentais para esses fundos alcançarem seus objetivos.

Marques e Souza (2012) demonstraram a influência dos modelos de valuation no processo decisório dos fundos de venture capital e private equity no Brasil e identificaram que o modelo de fluxo de caixa descontado é o mais utilizado. Ademais, uma pesquisa nos Estados Unidos demonstrou que 95\% dos private equity utilizam o Fluxo de Caixa Descontado (DFC) na avaliação de uma empresa seguido da Análise de Múltiplos com posterior desconto em fluxo de caixa (VYDRZEL; SOUKUPOVÁ, 2012).

Dessa maneira, este estudo abrange a avaliação de uma empresa com base principalmente no modelo de fluxo de caixa descontado e seus múltiplos.

Se por um lado observam-se o fortalecimento, um aumento e uma perspectiva crescente da indústria de private equity utilizam os relatórios contábil-financeiros na sua tomada de decisão em relação a investimentos. Por outro, identifica-se um aumento das informações evidenciadas e divulgadas nas demonstrações financeiras das empresas, que nem sempre resulta em aumento de qualidade.

\subsection{FLUXO DE CAIXA DESCONTADO}

A metodologia de fluxo de caixa descontado é a projeção do fluxo de caixa esperado por um período, mais o valor terminal calculado ao final desse período, descontado o valor presente por uma taxa que reflete a atualização monetária, o grau de risco e o retorno esperado do valor investido (CUNHA; MARTINS; ASSAF NETO, 2014; ALVIM; COSTA; COSTA, 2011; DAMODARAN, 2007; PALEPU; HEALY, 2004; SAURIN; COSTA JÚNIOR; ZILIO, 2007).

Desse modo, entende-se que a utilização de projeções e de uma taxa de desconto são essenciais no modelo de avaliação por meio do Fluxo de Caixa Descontado. Para se obter o fluxo de caixa esperado, fluxo de caixa livre, é relevante um ponto de partida, sendo este as projeções financeiras da empresa.

Alvim, Costa e Costa (2011), Copeland, Koller e Murrin (2002), Damodaran (2007), Saurin, Costa Júnior e Zilio (2007) asseveram que, para estimar o fluxo de caixa livre, os seguintes itens devem ser considerados: (a) vendas brutas, impostos sobre vendas, custo das vendas; (b) despesas operacionais, despesas não reembolsáveis, depreciação e amortização; (c) lucro da atividade - Earnings Before Interest, Taxes, Depreciation and Amortization (EBITIDA); (d) lucro operacional líquido de impostos - Net Operational Profit After Taxes (NOPAT); (e) gastos de capital e (f) necessidade de capital de giro.

As projeções dos itens anteriormente mencionados, devem ser baseadas na performance histórica da empresa, contemplando também perspectivas de futuro.

A taxa de desconto deve refletir a atualização monetária, o grau de risco dos fluxos de caixa, o custo do investimento, com seu prêmio, e a perpetuidade. Geralmente, utiliza-se a taxa média ponderada do custo de capital - weighted average cost of capital (WAAC), pois reflete as requeridas taxas de retorno para a dívida e para o patrimônio líquido com base nos valores 
esperados pelo mercado (DAMODARAN, 2007; KOLLER; GOEDHART; WESSELS, 2005; SAURIN; COSTA JÚNIOR; ZILIO, 2007).

O custo de capital é a necessidade de uma retribuição atraente para a captação dos recursos necessários. Logo, trata-se da remuneração que a companhia oferece aos fornecedores dos recursos, traduzida em rentabilidade do valor investido.

Tradicionalmente, como medida de retorno do capital investido e performance, tem sido utilizados o retorno sobre ativos - Return of Assets (ROA), o retorno sobre o patrimônio líquido - Return of Equity (ROE), o Valor Econômico Adicionado - Economic Value Added (EVA) e o Lucro antes dos Juros, Impostos, Depreciação e Amortização - Earnings Before Interest, Taxes, Depreciation and Amortization (EBITDA) (SANTOS; WATANABE, 2005; KOLLER; GOEDHART; WESSELS, 2005; ALVIM; COSTA; COSTA, 2011; DAMODARAN, 2007; SAURIN; COSTA JÚNIOR; ZILIO, 2007)

Com vistas a preparar uma avaliação de desempenho de uma companhia, é necessário rearranjar suas demonstrações financeiras, extrair valores e informações nas suas notas explicativas e, quando estes não estiverem disponíveis, deve-se estimar, pressupor com o máximo de detalhes possíveis.

\subsection{QUESTÕES RELEVANTES NA AVALIAÇÃO DE EMPRESAS RELACIONADAS ÀS INFORMAÇÕES DIVULGADAS NAS DEMONSTRAÇÕES CONTÁBEIS}

As demonstrações financeiras das companhias são elaboradas seguindo uma Estrutura Conceitual para Elaboração e Divulgação de Relatório Contábil-Financeiro. Esta define que o relatório contábil financeiro deve ser elaborado para os usuários externos em geral e que deve ser útil para estes tomarem suas decisões. Cabe, então, aos usuários ter condições de identificar nas demonstrações financeiras as informações relevantes (CPC, 2011; IASB, 2010; FASB, 2010; GLAUTIER; UNDERDOWN; MORRIS, 2011; CAMPELO, 2007; LIMA, 2010).

Ressalta-se, porém, que, apesar de a contabilidade objetivar ao apoio na tomada de decisões, está sujeita a ser influenciada pelos interesses dos administradores, dos proprietários, investidores e auditores que, muitas vezes, são divergentes. A qualidade das divulgações deriva do grau de custos e das vantagens que a companhia pode ter com estas.

Atualmente, as demonstrações financeiras apresentam um grande volume de informações dispersas e repetitivas, o que pode, por vezes, dificultar a identificação do que é relevante para a análise de desempenho de uma empresa, e para a tomada de decisões.

Desse modo, quando são analisados os relatórios das empresas a fim de estimar seus valores, é necessária uma análise detalhada das informações contábeis registradas e divulgadas, visando identificar possíveis itens que podem influenciar erroneamente a interpretação, o julgamento e a avaliação do possível investidor/analista.

Existem alguns itens nas demonstrações financeiras que merecem maior atenção, ou que o possível investidor/analista precisará obter mais informações em um processo de avaliação de empresa. Na maioria das vezes, as informações relativas a esses itens são somente divulgadas, mas nem sempre de forma concisa, clara e objetiva. A seguir, destaca-se sobre esses itens, sua importância e finalidade prática. 
Mudanças não explicadas nas práticas e políticas contábeis e nas estimativas, variações em receitas, custos, margens, contas a receber, estoques, são relevantes, uma vez que podem dar indícios sobre o andamento do negócio, sobre a existência de problemas operacionais, falhas nos controles internos, assim como possível administração de resultados (PALEPU; HEALY, 2004).

Diferenças entre lucro contábil, lucro fiscal e fluxo de caixa podem indicar que a rentabilidade é resultado de itens sem efeito caixa, que o lucro contábil talvez esteja superavaliado, o que afeta a expectativa de distribuição de dividendos e, consequentemente, as métricas relacionadas a rentabilidade (PALEPU; HEALY, 2004)

Quanto às provisões, Livinat e Santicchia (2006, p. 48, tradução nossa) afirmam que: "Um entendimento do que são as provisões e porque elas tendem a ser mais persistentes que o fluxo de caixa operacional líquido é importante para analistas e investidores por conta das suas implicações nos futuros lucros e retornos".

Os investimentos em participações societárias devem fazer parte do cálculo do valor de uma empresa, sendo essencial o entendimento do tratamento contábil de tais investimentos a fim de incluí-los no modelo de valorização. O mesmo se aplica aos ativos intangíveis. (DAMODARAN, 2007; KOLLER; GOEDHART; WESSELS, 2005).

O endividamento e os itens de capital de giro, de uma forma geral, são importantes, uma vez que possibilitam ao investidor avaliar a saúde financeira da empresa. $\mathrm{Na}$ avaliação pelo fluxo de caixa descontado, as dificuldades financeiras são consideradas por meio de ajuste nas taxas de desconto e nos fluxos de caixa esperados. Assim:

Fluxo de caixa esperado $=($ Fluxo de caixa continuidade $) \times($ probabilidade de que a empresa estará em continuidade operacional em certo período) + (Fluxo de caixa dificuldades) $\times$ (1- probabilidade de que a empresa estará em continuidade operacional em certo período). (DAMODARAN, 2007)

Com base no exposto, elaborou-se uma estrutura de avaliação de desempenho de companhias brasileiras pelos investidores de private equity, conforme as informações divulgadas nas demonstrações contábeis, apresentado no Apêndice A. A seguir, analisa-se a importância de cada item da estrutura com vistas a demonstrar sua finalidade prática.

- $\quad$ lucro não é considerado pelas empresas de private equity uma boa medida de desempenho, sendo os múltiplos de EBITDA indicativos de desempenho eleitos os melhores por essa indústria. Todavia, é a informação contábil da qual se parte para se obter as informações sobre geração de caixa, utilizadas como base para formulação das premissas dos fluxos de caixas descontados, sendo, inclusive, informação primordial para se obter o EBITDA.

- Itens que não afetam caixa, por exemplo, depreciação, amortização e resultado de equivalência patrimonial são relevantes, pois devem ser considerados como ajuste ao lucro e influenciam o cálculo do EBTDA.

- Os valores registrados como ajuste de avaliação patrimonial são reconhecidos em contas de patrimônio líquido, pois certas normas contábeis determinam. Ocorre que se esses itens afetam caixa no futuro, mesmo não fazendo parte das receitas e despesas da empresa, devem ser considerados nos cálculos do fluxo de caixa descontado.

Revista ENIAC Pesquisa, Guarulhos (SP), V.6, n.2, jun.- dez. 2017 
- $\quad$ No caso dos juros, deve-se primeiro segregar aqueles efetivamente pagos dos incorridos. $\mathrm{O}$ valor de despesa de juros auxilia na apuração da taxa de desconto a ser utilizada no desconto dos fluxos de caixa, além de ser uma medida que influencia o EBTDA.

- $\quad$ Os valores de impostos pagos, a reconciliação entre as alíquotas nominais e efetivas, os créditos fiscais utilizados e os incentivos fiscais obtidos pela empresa são úteis no processo de preparação das projeções de fluxo de caixa, já que podem indicar aumento ou redução de valores a serem desembolsados e impactam o fator perpetuidade.

- Ganhos e perdas com ajuste a valor justo de ativos podem ou não se materializar no futuro, impactar, assim, o processo de obtenção do fluxo de caixa descontado. Também podem dar indícios em relação à atividade operacional, como a empresa está posicionada no mercado, sua capacidade de crescimento entre outros.

- $\quad$ Perdas reais são dados históricos que podem auxiliar na previsão de possíveis perdas futuras e na avaliação se essas devem ou não ser consideradas nas projeções. Ademais são úteis na análise da atividade operacional da empresa e na avaliação dos seus procedimentos e controles internos.

- As contingências precisam ser avaliadas, pois os valores podem ou não ser requeridos no futuro, o que impacta a estimação do valor da empresa. Durante o processo de due diligence, são avaliadas as perdas reais, as provisões registradas e as contingências possíveis, sendo seus valores estimados e descontados do preço a ser pago, ou bloqueados, sendo pagos, ou efetivamente deduzidos do preço, à medida em que as contingências são resolvidas.

- $\quad$ Plano de pensão pós-emprego, passivos atuariais, pagamentos com base em ações, instrumentos de dívidas conversíveis em ações e alguns híbridos, usualmente, têm seus valores justos estimados com os ganhos e perdas registrados no patrimônio líquido ou no resultado. Contudo, estes valores serão realizados a médio ou longo prazo, são subjetivos, sendo necessária uma avaliação minuciosa de como serão considerados nas projeções.

- $\quad$ O nível de endividamento, o arrendamento mercantil financeiro, as despesas financeiras e o capital de giro possibilitam ao analista observar se a empresa está sendo financiada por capital próprio ou de terceiros, se tem capacidade de cumprir com suas obrigações, e, se não o fizer, quais os bens dados em garantia que serão executados, se haverá quebra de covenants, entre outros aspectos.

- A remuneração aos acionistas possibilita estimar o nível do retorno do capital investido. Todavia, o ROE/ROIC e o ROA, tradicionalmente, têm sido as medidas de performance utilizadas, uma vez que demonstram a rentabilidade da empresa em relação ao capital investido e aos investimentos em ativos, respectivamente.

O EBITDA e o NOPAT estão relacionados ao lucro operacional, sendo o primeiro o lucro operacional englobando os impostos, e o segundo, o líquido de impostos. Em resumo, trata-se do lucro da atividade menos o custo de capital empregado. O WACC é a taxa mais utilizada pelo mercado para se descontar o fluxo de caixa livre
da empresa. O WACC é a taxa mais utilizada pelo mercado para se descontar o fluxo de caixa livre
da empresa. 
As principais estratégias da empresa, a composição das receitas, o comportamento das vendas, os custos, as margens, variações significativas nas contas contábeis e suas respectivas explicações, são informações relevantes para elaboração das premissas que serão utilizadas para obter o fluxo de caixa livre.

Ressalvas e parágrafos de ênfase nos pareceres dos auditores podem indicar a existência de erros, incertezas, riscos, problemas nos controles internos, entre outros detalhes que devem ser considerados no processo de precificação da empresa, já que podem resultar em eventuais ganhos ou perdas futuras.

\section{METODOLOGIA DE PESQUISA}

Efetuou-se uma pesquisa com base na técnica de análise documental, utilizando-se uma abordagem quantitativa e qualitativa.

Realizou-se uma pesquisa bibliográfica a fim de se identificar os elementos relevantes na avaliação de uma empresa e, a partir daí, definiu-se os itens que seriam contemplados na estrutura de avaliação de desempenho desenvolvida e apresentada no Apêndice A.

Para corroborar o achado, efetuou-se uma triangulação entre os itens mencionados na estrutura de avaliação de desempenho anteriormente comentada e as informações divulgadas pelas empresas da amostra, objetivando identificar se eles estão contemplados nas demonstrações financeiras e/ou podem ser calculados por meio das informações apresentadas. Os dados resultantes desta análise foram organizados e agrupados em tabelas utilizando-se a técnica de estatística descritiva.

Ao considerar o perfil das empresas-alvo das entidades de private equity e a disponibilidade de dados, conclui-se que as companhias listadas no segmento Bovespa Mais seriam mais adequadas para o desenvolvimento desta pesquisa.

Ocorre que o interesse dos gestores dos fundos de private equity é em setores específicos, sendo os três principais Energia e Energias Renováveis, Agronegócio e Tecnologia da Informação (KPMG, 2014). Logo, as empresas desses setores, listadas no segmento Bovespa Mais, foram as selecionadas para a pesquisa.

Avaliou-se a necessidade temporal da informação relevante para os private equity e observou-se que esses estão interessados na situação atual e nas perspectivas de futuro da empresa. Logo, conclui-se que a data base mais adequada para a aplicação da pesquisa é o período mais recente das demonstrações financeiras anuais publicadas.

Desse modo, obteve-se como amostra as demonstrações financeiras com exercício findo em 31.12.2014 das empresas listadas no Bovespa Mais que atuam nos segmentos de energia e energias renováveis, agronegócio e tecnologia da informação, sendo elas:

Energia Renovável:

a) Cia Águas do Brasil - CAB Ambiental (CAB), e

b) Desenvix Energias Renováveis S.A. (Desenvix) 
Tecnologia da Informação:
a) Quality Software S.A. (Quality), e
b) Senior Solution S.A. (Senior)

\section{RESULTADOS}

Desenvolveu-se uma estrutura de avaliação de desempenho com base nas informações divulgadas nas demonstrações financeiras de companhias brasileiras, que sejam úteis para os fundos de private equity avaliarem empresas, onde pretendem investir e aquelas nas quais já têm participação.

Dos 66 itens apresentados na estrutura de avaliação de desempenho, seis deles (9\%) não foram aplicáveis a nenhuma das empresas constantes da amostra, provavelmente por se tratar de transações não usuais e complexas, normalmente identificadas em empresas mais desenvolvidas e estruturadas.

Observa-se que 11 itens (17\%) não foram informados por nenhuma das empresas. Isso deriva do fato de que a divulgação destes não é requerida pelas normas de contabilidade e também, de estarem relacionados à estratégia operacional e financeira da empresa.

Em contrapartida, 38 itens estiveram presentes em mais de $60 \%$ das empresas da amostra, representando $58 \%$ do total de itens contemplados na estrutura desenvolvida.

Ademais, 27 itens da estrutura de avaliação de desempenho desenvolvida estiveram presentes em $100 \%$ das demonstrações financeiras pesquisadas, isto é, $41 \%$ foram divulgados por todas as empresas objetos deste estudo.

Analisando a Tabela 1, observa-se que a média de presença dos itens da estrutura de avaliação de desempenho desenvolvida nas demonstrações financeiras pesquisadas é de $66,02 \%$, sendo a empresa Quality Solution S.A. aquela com o menor índice de divulgação, $48,08 \%$ e a CAB Ambiental com o maior índice - 73,08\%.

Também, observa-se que o segmento de Energia Renovável tem uma média percentual de presença dos itens da estrutura da avaliação de desempenho desenvolvida melhor que a do segmento de Tecnologia da Informação, sendo, respectivamente $73 \%$ e 59\%. 
Tabela 1 - Observação percentual quanto à presença dos itens apresentados na estrutura de avaliação de desempenho de companhias brasileiras pelos investidores de private equity nas demonstrações financeiras das empresas da amostra - no ano de 2014.

\begin{tabular}{|c|c|c|c|c|c|c|c|c|c|}
\hline \multirow[b]{2}{*}{ Empresas } & \multicolumn{2}{|c|}{ Divulgado } & \multirow{2}{*}{\multicolumn{2}{|c|}{$\%$}} & \multicolumn{2}{|c|}{$\begin{array}{l}\text { Não } \\
\text { Aplicável }\end{array}$} & \multirow[b]{2}{*}{ Aplicáveis } & \multirow[b]{2}{*}{$\begin{array}{l}\text { Percentual } \\
\text { de Presença }\end{array}$} & \multirow[b]{2}{*}{$\begin{array}{l}\text { Total } \\
\text { Geral }\end{array}$} \\
\hline & & $\%$ & & & & $\%$ & & & \\
\hline QUALITY & 25 & $37,88 \%$ & 27 & $40,91 \%$ & 14 & $21,21 \%$ & 52 & $48,08 \%$ & 66 \\
\hline SENIOR & 38 & $57,58 \%$ & 16 & $24,24 \%$ & 12 & $18,18 \%$ & 54 & $70,37 \%$ & 66 \\
\hline DESENVIX & 37 & $56,06 \%$ & 14 & $21,21 \%$ & 15 & $22,73 \%$ & 51 & $72,55 \%$ & 66 \\
\hline $\mathrm{CAB}$ & 38 & $57,58 \%$ & 14 & $21,21 \%$ & 14 & $21,21 \%$ & 52 & $73,08 \%$ & 66 \\
\hline Média & & 34,5 & & 17,75 & & 13,75 & 52,25 & $66,02 \%$ & 66 \\
\hline Total & & 138 & & 71 & & 55 & 209 & & 264 \\
\hline
\end{tabular}

Fonte: Dados da pesquisa, 2017.

Apesar de itens como Fluxo de Caixa Livre - Free Cash Flow (FCF), WACC e dados históricos sobre as operações não serem divulgados, o alto índice da média da presença dos itens da estrutura desenvolvida nas demonstrações financeiras das empresas analisadas indica que os itens constantes da estrutura são importantes na avaliação de desempenho das empresas. Adicionalmente, corrobora a possibilidade da utilização de tal estrutura no processo de estimação do valor de uma empresa.

\section{CONSIDERAÇÕES FINAIS}

As demonstrações financeiras apresentam um grande volume de informações que, muitas vezes, não são compreensíveis. Por outro lado, os private equity precisam que as informações relativas à avaliação de desempenho de uma empresa sejam apresentadas de uma maneira clara, objetiva, prática, para que possam estimar o valor de uma empresa-alvo e analisar a rentabilidade de seus investimentos.

Por meio de pesquisa bibliográfica, identificaram-se os elementos relevantes na avaliação de uma empresa e, a partir daí, desenvolveu-se uma estrutura de avaliação de desempenho de companhias brasileiras, a partir das informações divulgadas em suas demonstrações financeiras, a fim de auxiliar os investidores de private equity na estimação do valor de uma entidade, valuation.

Pela avaliação do conteúdo das demonstrações financeiras de 31 de dezembro de 2014, das quatro empresas registradas no Bovespa Mais dos segmentos de Energia Renovável e Tecnologia da Informação, identificou-se que: dos 66 itens contemplados na estrutura desenvolvida, 9\% não foram aplicáveis a nenhuma das empresas constantes da amostra; $17 \%$ não foram informados por nenhuma das empresas constantes da amostra; 58\% estiveram presentes em mais de $60 \%$ das demonstrações financeiras das empresas objeto da amostra e $41 \%$ foram divulgados por todas as empresas.

Revista ENIAC Pesquisa, Guarulhos (SP), V.6, n.2, jun.- dez. 2017 
Os itens não aplicáveis são transações não usuais e complexas, normalmente identificadas em empresas mais desenvolvidas e estruturadas. Os itens não informados por nenhuma das empresas são essenciais na precificação de uma empresa; logo, sugere-se que sejam evidenciados ou divulgados nas demonstrações financeiras.

A média de presença dos itens da estrutura de avaliação de desempenho desenvolvida nas demonstrações financeiras pesquisadas é de 66,02\%. O segmento de Energia Renovável tem uma média percentual de presença dos itens superior à média do segmento de Tecnologia da Informação. Ademais, os auditores independentes das empresas desse segmento são entidades que fazem parte das quatro maiores empresas de auditoria do mundo.

Diante do exposto, pode-se concluir que o objetivo proposto neste estudo foi alcançado, pois o alto índice da média da presença dos itens da estrutura de avaliação de desempenho desenvolvida nas demonstrações financeiras das empresas analisadas corrobora a possibilidade da utilização de tal estrutura no processo de estimação do valor de uma empresa.

Observa-se, ainda, que itens como Free Cash Flow, WAACC e dados históricos sobre as operações poderiam ser divulgados, à medida em que as notas explicativas das demonstrações financeiras fossem aprimoradas. Cabe lembrar que o IASB (International Accounting Standard Board) tem um projeto chamado Disclosure Initiative, que objetiva explorar como as divulgações em IFRS poderiam ser melhoradas, englobando, inclusive, expectativas de futuro para se tornarem mais úteis, principalmente aos investidores e credores (IASB, 2014).

No decorrer desta pesquisa, identificou-se a oportunidade de novas pesquisas relacionadas ao tema. Sugere-se obter a opinião dos investidores de private equity acerca da aplicabilidade da estrutura de avaliação de desempenho desenvolvida.

\section{REFERÊNCIAS}

ABVCAP - ASSOCIAÇÃO BRASILEIRA DE PRIVATE EQUITY \& VENTURE CAPITAL. ABVCAP e KPMG divulgam estudo que mostra aumento capital disponível para investimentos no setor de private equity. 7 abr. 2015. Disponível em: $<$ http://www.abvcap.com.br/sala-de-imprensa/noticias-abvcap.aspx?c=pt-BR\&id=3018>. Acesso em: 29 abr. 2015.

CAMPELO, K. S. et al. Características qualitativas da informação contábil: uma análise do grau de entendimento dos gestores financeiros das empresas do setor elétrico brasileiro. 2007. 122 f. Dissertação (Mestrado em Ciências Contábeis). Universidade Federal de Pernambuco. Recife, 2007.

CPC - COMITÊ DE PRONUNCIAMENTOS CONTÁBEIS. CPC 00 (R1) - Estrutura conceitual para elaboração e divulgação de relatório contábil-financeiro. Brasília, dez. 2011. Disponível em: $\quad<$ http://www.cpc.org.br/CPC/DocumentosEmitidos/Pronunciamentos/Pronunciamento?Id=80>. Acesso: 5 ago. 2014. 
COPELAND, T.; KOLLER, T.; MURRIN, J. Avaliação de empresas: valuation: calculando e gerenciando o valor das empresas. 3. ed. São Paulo: Makron Books, 2002.

ALVIM, M. A.; COSTA, L. G. T. A.; COSTA, L. R. T. A. Valuation: manual de avaliação e reestruturação econômica de empresas. 2. ed. São Paulo: Atlas, 2011.

CVM - COMISSÃO DE VALORES MOBILIÁRIOS. Instrução CVM n. 391, de 16 de julho de 2003, que dispõe sobre a Constituição, o funcionamento e a administração dos Fundos de Investimentos em Participações. Disponível em: $<$ www.cvm.gov.br/asp/cvmwww/Atos/Atos/inst/inst391consolid.doc $>$. Acesso em: 3 out. 2014.

CUNHA, M. F.; MARTINS, E.; ASSAF NETO, A. Avaliação de empresas no Brasil pelo fluxo de caixa descontado: evidências empíricas sob o ponto de vista dos direcionadores de valor nas ofertas públicas de aquisição de ações. Revista de Administração, São Paulo, SP, v. 49, n. 2, p. 251-266, abr./maio/jun. 2014. Disponível em: $<$ http://www.scielo.br/pdf/rausp/v49n2/04.pdf >. Acesso em: 30 jul. 2014.

DAMODARAN, A. Avaliação de empresas. 2. ed. São Paulo: Pearson Prentice Hall, 2007.

FASB - FINANCIAL ACCOUNTING STANDARDS BOARD. Statement of financial accounting concepts n. 8: conceptual framework for financial reporting. New York, Sept. 2010. Disponível

$<$ http://www.fasb.org/cs/BlobServer?blobkey=id\&blobnocache $=$ true \&blobwhere $=117582289$ 2635\&blobheader=application\%2Fpdf\&blobheadername2=Content-

Length\&blobheadername $1=$ Content

Disposition\&blobheadervalue $2=210323 \&$ blobheadervalue $1=$ filename\%3DConcepts_Stateme nt_No_8.pdf\&blobcol=urldata\&blobtable=MungoBlobs $>$. Acesso em: 5 ago. 2014.

GLAUTIER, M. E. W; UNDERDOWN, B.; MORRIS, D. Accounting theory and practice. 8th ed. New York: Financial Times Prentice Hall, 2011.

IASB - INTERNATIONAL ACCOUNTING STANDARD BOARD. The conceptual framework for financial report. Londres, Sept. 2010. Disponível em: $<$ http://eifrs.ifrs.org/eifrs/bnstandards/en/2014/conceptual_framework_unaccompanied.pdf $>$. Acesso em: 5 ago. 2014.

Disclosure initiative. Londres, Sept. 2014. Disponível em: $<$ http://www.ifrs.org/Current-Projects/IASB-Projects/Disclosure-Initiative/Pages/DisclosureInitiative.aspx>. Acesso em: 1 out. 2014.

KOLLER, T; GOEDHART, M.; WESSELS, D. Valuation: measuring and managing the value companies. 4. ed. Hoboken, NJ: John Wiley \& Sons, 2005.

KPMG AUDITORES INDEPENDENTES; ABVCAP - ASSOCIAÇÃO BRASILEIRA DE PRIVATE EQUITY \& VENTURE CAPITAL. Consolidação de dados da indústria de Private Equity e Venture Capital no Brasil: 2011, 2012, 2013. Disponível em: $<$ http://abvcap.com.br/Download/Estudos/2716.pdf>. Acesso em: 3 out. 2014. 
LIMA, I. G. Índice de Conformidade de Evidenciação (ICE): uma aplicação. 2010. 133 f. Dissertação (Mestrado em Ciências Contábeis) - Fundação Escola de Comércio Álvares Penteado - FECAP, São Paulo, 2010.

LIVINAT, J.; SANTICCHIA, M. Quarterly Cash flows, accruals and future returns. Financial Analysts Journal, Charlottesville, Virginia, v. 62, n. 4, p. 48-61, jul./aug. 2006. Disponível em: <http://www.cfapubs.org/doi/abs/10.2469/faj.v62.n4.4186>. Acesso em: 30 jul. 2014.

MARQUES, V. A.; SOUZA, A. A. A influência dos modelos de valuation no processo decisório dos fundos de Venture Capital/Private Equity. Revista de Finanças Aplicadas, São Paulo, SP, v. 1, p. 1-17, mai. 2012. Disponível em: $<$ http://www.financasaplicadas.net/ojs/index.php/financasaplicadas/article/viewArticle/51>. Acesso em: 03 out. 2014.

PALEPU, K. G.; HEALY, P. M. Business analysis and valuation: using financial statements. 4th ed. Mason, $\mathrm{OH}$ : Thomson, 2004.

SANTOS, J. O.; WATANABE, R. Uma análise da correlação entre o EVA ${ }^{\circledR}$ e o MVA ${ }^{\circledR}$ no Contexto das Empresas Brasileiras de Capital Aberto. Caderno de Pesquisas em Administração, São Paulo, v. 12, n. 1, p. 19-32, jan./mar. 2005. Disponível em: $<$ http://www.revistas.usp.br/rege/article/view/36507>. Acesso em: 30 set. 2014.

SAURIN, V.; COSTA JÚNIOR, N. C. A.; ZILIO A. C. S. Estudo dos modelos de avaliação de empresas com base na metodologia do fluxo de caixa descontado: estudo de caso. Revista de Ciências da Administração, São Paulo, v. 9, n. 18, p. 123-148, maio/ago. 2007.

SMOLARSKI, J.; WILNER, N.; YANG, W. The use of financial information by private equity funds in evaluating new investments. Review of Accounting and Financial. Bingley, UK, v. 10, p. 46-68, dez. 2011. Disponível em: $<$ http://www.emeraldgrouppublishing.com/about/index.htm>. Acesso em: 30 set. 2014.

VYDRZEL, K.; SOUKUPOVÁ, V. Empirical examination or valuation methods used in private equity practice in Czech Republic. The Journal of Private Equity. New York, v. 16, n. 1 dec. $2012 . \quad$ Disponível <http://www.iijournals.com/doi/abs/10.3905/jpe.2012.15.4.089>. Acesso em: 30 set. 2014. 
APÊNDICE A

ESTRUTURA DE AVALIAÇÃO DE DESEMPENHO DE COMPANHIAS

BRASILEIRAS PELOS INVESTIDORES DE PRIVATE EQUITY BASEADA NAS

INFORMAÇÕES DIVULGADAS NAS DEMONSTRAÇÕES CONTÁBEIS

\begin{tabular}{|l|l|}
\hline Itens & Informações Necessárias \\
\hline Resultado do exercício & \\
\hline Geração de caixa & \\
\hline Itens que não afetam caixa & \\
\hline $\begin{array}{l}\text { Ganhos e perdas não recorrentes registrados na demonstração do } \\
\text { resultado do exercício }\end{array}$ & \\
\hline $\begin{array}{l}\text { Ganhos e perdas registrados em conta do patrimônio líquido que irão } \\
\text { transitar pelo resultado do exercício no futuro - Ajuste de avaliação } \\
\text { patrimonial }\end{array}$ & \\
\hline Juros & \\
\hline Depreciação e Amortização & \\
\hline Impostos pagos & \\
\hline Impostos que podem vir a ser pagos derivados de diferenças temporárias & \\
\hline Alíquotas nominal e efetiva do imposto de renda e contribuição social & \\
\hline $\begin{array}{l}\text { Reconciliação entre as alíquotas nominal e efetiva do imposto de renda e } \\
\text { contribuição social }\end{array}$ & \\
\hline Créditos fiscais utilizados no ano & \\
\hline Incentivos fiscais & \\
\hline Ativos Não Operacionais & \\
\hline $\begin{array}{l}\text { Ajustes relativos a redução a valor recuperável (impairment) e redução a } \\
\text { valor realizável. }\end{array}$ & \\
\hline $\begin{array}{l}\text { Ganhos e perdas com ajustes a valor justo de imobilizado, investimentos } \\
\text { e intangíveis }\end{array}$ & \\
\hline Perdas reais com contar a receber & \\
\hline Perdas reais com estoques & \\
\hline Perdas reais com imobilizado & \\
\hline Perdas reais com investimentos & \\
\hline Provisões para contingências & \\
\hline Perdas reais com contingências & \\
\hline Contingências possíveis & \\
\hline Planos de pensão e pós emprego & \\
\hline Passivos atuariais derivados de plano de pensão e pós emprego & \\
\hline Valores dos ajustes dos passivos atuariais no ano & \\
\hline Pagamento baseado em ações concedido a funcionário e ou terceiros & \\
\hline Instrumentos híbridos de patrimônio líquido e dívidas & \\
\hline Instrumentos de dívida conversíveis em ações & \\
\hline Intangíveis reconhecidos ou não nas demonstrações financeiras & \\
\hline Investimentos e suas técnicas de avaliação & \\
\hline $\begin{array}{l}\text { Resultado dos investimentos em outras empresas por técnica de } \\
\text { valorização. }\end{array}$ & \\
\hline Caixa e equivalente de caixa & \\
\hline Resultado dos investimentos no mercado financeiro & \\
\hline Transações com partes relacionadas & \\
\hline Remuneração aos acionistas (dividendos, JCP, outros) & \\
\hline Itens que compõe o capital de giro & \\
\hline
\end{tabular}

Revista ENIAC Pesquisa, Guarulhos (SP), V.6, n.2, jun.- dez. 2017 


\begin{tabular}{|l|l|}
\hline Total do endividamento de curto prazo & \\
\hline Total do endividamento de longo prazo & \\
\hline Total dos arrendamentos mercantis financeiros & \\
\hline Total do Endividamento & \\
\hline Taxa média de juros das captações & \\
\hline Despesas financeiras & \\
\hline Garantias concedidas & \\
\hline Quebra de covenants & \\
\hline Reestruturação de dívidas & \\
\hline Capital social & \\
\hline Quantidade de ações preferenciais & \\
\hline Quantidade de ações ordinárias & \\
\hline Quantidade e valor de ações em tesouraria & \\
\hline Reserva para investimentos & \\
\hline Return Over Equity - ROE & \\
\hline Return Over Asset - ROA & \\
\hline Return of Invested Capital - ROIC & \\
\hline Non Operating Profit After Taxes - NOPAT & \\
\hline $\begin{array}{l}\text { Earnings Before Taxes, Interest, Depreciation and Amortization- } \\
\text { EBTIDA }\end{array}$ & \\
\hline Weighted Average Cost of Capital - WAAC & \\
\hline Free Cash Flow - FCF & \\
\hline Composição das receitas & \\
\hline Composição dos custos & \\
\hline Comportamento das vendas, custo, margens & \\
\hline Contas contábeis com variações significativas & \\
\hline$\bullet \quad$ Principais estratégias da Empresa: & \\
$\bullet \quad$ Novos Produtos & \\
$\bullet \quad$ Novos Mercados & \\
$\bullet \quad$ Aquisições & \\
$\bullet \quad$ Reestruturações & \\
\hline Principais riscos & \\
$\bullet \quad$ Operacionais & \\
$\bullet \quad$ Financeiros & \\
\hline $\begin{array}{l}\text { Existência de ressalvas e parágrafos de ênfase no relatório de } \\
\text { auditoria }\end{array}$ & \\
\hline
\end{tabular}

Fonte: Elaborado pelos autores, 2017.

Revista ENIAC Pesquisa, Guarulhos (SP), V.6, n.2, jun.- dez. 2017 